\title{
MINI SERVER LENTERA SEBAGAI ALTERNATIF PEMBELAJARAN DIGITAL DI DAERAH 3T
}

\author{
Ganefri $^{1}$, Bayu Ramadhani Fajri ${ }^{2}$, Fadhli Ranuharja ${ }^{3}$, Febri Prasetya ${ }^{4}$, \\ Rahmat Fadillah ${ }^{5}$, Firdaus ${ }^{6}$ \\ ${ }^{1}$ Teknik Elektro, ${ }^{236}$ Prodi Pendidikan Teknik Informatika, ${ }^{4}$ Prodi Pendidikan Teknik Mesin, \\ ${ }^{5}$ Pasca Sarjana Pendidikan Teknologi Kejuruan, \\ Fakultas Teknik, Universitas Negeri Padang \\ e-mail: ganefri@ft.unp.ac.id, bayurf@unp.ac.id,fadhliranu@ft.unp.ac.id, febriprasetya@ft.unp.ac.id, \\ rahmat.fadillah.ft.unp@gmail.com, firdaus171098@gmail.com
}

\begin{abstract}
The purpose of this activity is to design a mini server with digital learning content to serve as an alternative learning medium for remotes areas high schools teachers and students in the West Sumatra. The content on this mini server can be used by teachers and students in the digital learning process not only in remote areas, but also can be used in urban areas because this tool offers flexible access without internet network. The background of this innovation is the mismatch between the demands of the government who want the implementation of digital and online learning and the implementation of the Computer Based National Examination. But on the other hand, schools forbid students from bringing gadgets to school for fear that students will access sites and negative content that is not relevant to learning. The learning material presented in this device is in the form of video, audio, and various content compiled on the offline site so students can access using a gadget or personal computer (PC) without the need for an internet connection. The system design on this device uses 2 types of approaches, namely network design for mini servers and the design of the Unified Modeling Language (UML) modeling system for systems that work on devices as mini servers.
\end{abstract}

Keywords: Mini server, Remote areas, Digital learning

\section{INTISARI}

Tujuan kegiatan ini adalah untuk merancang mini server dengan konten pembelajaran digital untuk sebagai media pembelajaran alternatif bagi guru dan siswa sekolah menengah daerah 3T di wilayah Sumatera Barat. Konten pada mini server ini dapat dimanfaatkan oleh guru dan siswa dalam proses pembelajaran digital tidak hanya di daerah $3 \mathrm{~T}$ saja, namun juga dapat digunakan di daerah perkotaan karena alat ini menawarkan akses yang fleksibel tanpa jaringan internet. Latarbelakang inovasi ini adalah ketidaksesuaian antara tuntutan pemerintah yang menginginkan implementasi pembelajaran digital dan online dan implementasi Ujian Nasional Berbasis Komputer. Namun di sisi lain, sekolah melarang siswa membawa gadget ke sekolah karena khawatir siswa akan mengakses situs dan konten negatif yang tidak relevan dengan pembelajaran. Materi pembelajaran yang disajikan dalam perangkat ini adalah dalam bentuk video, audio, dan berbagai konten yang dikompilasi di situs offline sehingga siswa dapat mengakses menggunakan gadget atau komputer pribadi (PC) tanpa memerlukan koneksi internet. Perancangan sistem pada perangkat ini menggunakan 2 jenis pendekatan, yaitu desain jaringan untuk mini server dan desain sistem pemodelan Unified Modeling Language (UML) untuk sistem yang bekerja pada perangkat sebagai mini server.

Kata kunci : Mini server, Remote areas, Pembelajaran digital 


\section{PENDAHULUAN}

Teknologi informasi dan komunikasi telah mengubah cara dan proses belajar. Pesatnya pertumbuhan Teknologi Informasi dan Komunikasi saat ini membuat dunia maya memiliki berbagai macam informasi atau sumber belajar yang tidak terbatas [1]. Literasi informasi yang mencakup kemampuan mengakses, mengevaluasi dan menggunakan informasi sangat penting dikuasai oleh siswa pada saat ini. Literasi ICT berpusat pada keterampilan berpikir tingkat tinggi dalam mempertimbangkan informasi, media, dan teknologi di lingkungan sekitar. Terdapat beberapa keterkaitan antara tiga bentuk literasi yang meliputi literasi komunikasi informasi, media dan teknologi. Penguasaan terhadap keterampilan tersebut memungkinkan penguasaan terhadap keterampilan dan kompetensi lain yang diperlukan untuk keberhasilan kehidupan di abad ke-21. Kemampuan literasi ICT ini dapat dikuasai oleh siswa dengan memanfaatkan gawai yang sudah melekat dalam kehidupan sehari-hari siswa. Pemanfaatan teknologi informasi dalam proses pembelajaran mampu menjadikan jarak dan tempat tidak lagi menjadi alasan bagi seseorang untuk menciptakan pengembangan pembelajaran yang terencana terarah dan berkesinambungan dengan kebutuhan saat ini [2].

Namun kondisi di lapangan belum sepenuhnya mendukung keterlaksanaan pembelajaran abad 21 [4] khususnya di provinsi Sumatera Barat. Masih banyak sekolah yang melarang siswa menggunakan smartphone karena khawatir siswa akan mengakses konten negatif dan tidak relevan dengan pembelajaran. Kekhawatiran guru apabila siswa diizinkan untuk terhubung dengan internet masih banyak terjadi di sekolah. Mudahnya akses ke dunia luar, menjadi momok tersendiri bagi sebagian besar guru di Sumatera Barat sehingga membatasi bahkan melarang penggunaan gadget dan perangkat internet yang merupakan fasilitas minimum yang diperlukan siswa untuk dapat mengakses konten pembelajaran digital.

Disisi lain, pemerintah menuntut pembelajaran digital dan online serta pelaksanaan Ujian Nasional Berbasis Komputer. Menjawab permasalahan tersebut, diperlukan sebuah media/alat yang dapat digunakan untuk proses pembelajaran digital yang menyediakan fasilitas latihan ulangan dalam jaringan serta menyediakan konten bahan ajar digital yang dapat diakses melalui perangkat smartphone peserta didik tanpa harus terkoneksi dengan internet.

\section{METODE}

Kegiatan ini menggunakan 2 metode perancangan. Pertama adalah metode perancangan jaringan menggunakan jaringan lokal menggunakan akses poin. Metode ini menghasilkan analisis kebutuhan hardware, analisis kebutuhan software. Perancangan sistem dilakukan dengan menggunakan pemodelan UML(Unified Modelling Language) karena dianggap sebagai bahasa pemodelan yang dapat menggambarkan sistem secara utuh [3]. Kedua adalah perancangan sistem aplikasi berbasis web menggunakan pemodelan Unified modeling language untuk mendapatkan data analisis pengguna menggunakan diagram use case, analisis alur sistem mengunakan diagram konteks analisis urutan alur sistem menggunakan diagram sequence dan yang terakhir normalisasi basis data untuk menetapkan data apa saja yang akan diolah di sistem ini. Penggabungan ini diterapkan ke dalam sebuah produk prototype mini server LENTERA sebagai media pembelajaran interaktif digital [5].

\section{PEMBAHASAN}

\section{A. Perancangan Jaringan Lokal Nirkabel}

\section{Analisis Hardware}

Analisis hardware merupakan persiapan untuk menyediakan alat perangkat jaingan yang dibutuhkan. Dalam menerapkan penelitian ini dibutuhkan alat yag menjadi server, client dan media penghubung jaringan.

a. Clients Server Device

Untuk produk LENTERA ini rassberry pi adalah sebuah mini server yang bisa menampung setidaknya 30 user secara bersamaan, menggunakan

1) Mini server rasberry pi + digunakan:

Berikut spesifikasi raspberry pi yang

* SoC: Broadcom BCM2837

* CPU: 4x ARM Cortex-A53, 1.2GHz

* GPU: Broadcom VideoCore IV

* RAM: 1GB LPDDR2 (900 MHz)

* Networking: 10/100 Ethernet, 2.4GHz 802.11n wireless

* Bluetooth: Bluetooth 4.1 Classic, Bluetooth Low Energy

* Storage: microSD

* GPIO: 40-pin header, populated

* Ports: HDMI, 3.5mm analogue audio-video jack, 4x USB 2.0, Ethernet, Camera Serial Interface (CSI), Display Serial Interface (DSI) 


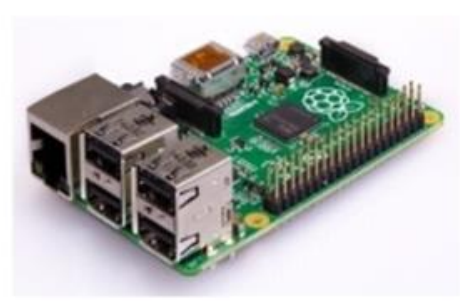

Gambar 1. Raspberry pi type B+

\section{2) Client device}

Implementasi clients pada produk media literasi digital LENTERA cukup menggunakan PC yang memiliki penangkap sinyal wi-fi standar. Untuk studi kasus daerah yang minim fasilitas perangkat client dapat berupa smartphone android.

\section{b. Network device}

Pada bagian radio network device ini ukurannya sangat kecil, hanya bisa dilihat dengan menggunakan mikroskop atau kaca pembesar, chip Broadcom BCM43438 menyediakan LAN nirkabel standar 2,4GHz 802.11n, Bluetooth rendah daya, dan dukungan Bluetooth 4.1. Chip radionya sudah terhubung dengan chip antenna ini yang disolder langsung ke board, untuk menjaga ukurannya tetap ramping dan minimum. Antenna ini lebih dari cukup untuk bisa menangkap sinyal Wi-Fi dan Bluetooth meskipun terhalang dinding

\section{Analisis Kebutuhan software}

Membuat media mini server tentu menggunakan sebuah platform yang akan mengatur lalu lintas data dari client yang akan beroperasi secara terus menerus. Platform sistem operasi yang berjalan di raspberry pi yang dipilih adalah Raspbian. Sistem operasi rasbian adalah sistem ringan berbasis distribusi debian yang dinilai handal dan cocok untuk menjadi sistem operasi pada mini server LENTERA.

\section{Topologi Jaringan LENTERA Sebagai Mini Server}

Topologi jaringan LENTERA merupakan topologi yang digunakan untuk pengujian fungsifungsi sistem media literasi digital learning di sekolah Berbasis Android apakah sudah sesuai dengan perencanaan atau belum. Adapun topologi jaringan dapat dilihat pada gambar berikut.

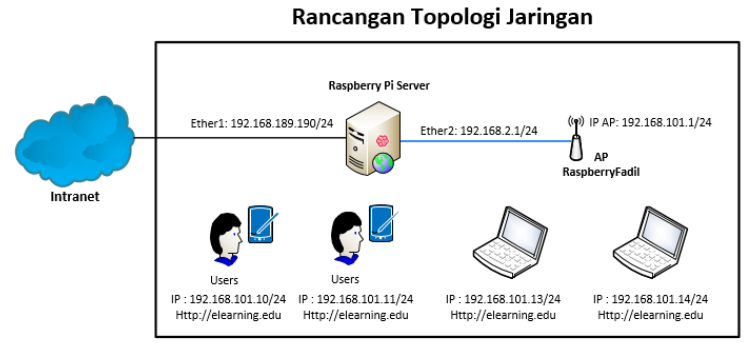

Gambar 2. Topologi Jaringan LENTERA

Topologi yang dibangun oleh perangkat LENTERA ini adalah jaringan local yang berpusat pada akses point yang terpasang pada mini server LENTERA. Kemudian jaringan lokal ini dihubungkan dengan perangkat smartphone/laptop yang disediakan untuk siswa. Jaringan ini telah disimulasikan dan dapat menampung 25 user untuk satu mini server di dalam kelas. Perangkat yang telah terhubung dengan jaringan mini server LENTERA dapat menggunakan aplikasi dengan mengketikkan alamat domain lokal lentera pada browser masing-masing.

\section{B. Perancangan Sistem Media Literasi Digital Learning LENTERA}

1. Analisis Kebutuhan Pengguna Menggunakan Use Case Diagram

Perancangan use-case diagram digunakan untuk mengetahui fungsi apa saja yang ada dalam sebuah sistem dan yang berhak melakukan hak akses, dapat dilihat pada gambar dibawah ini.

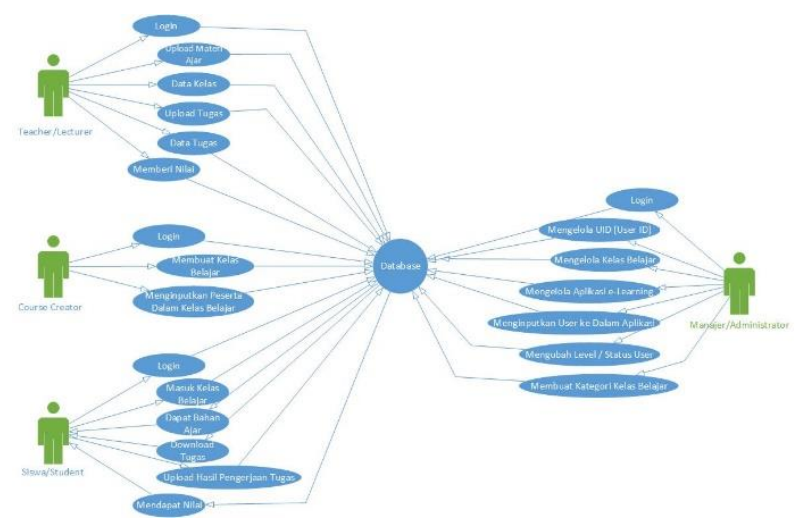

Gambar 3. Diagram Use Case System Mobile Learning LENTERA

a. Manajer/Administrator : Mengelola sistem, menginputkan data (server), mengelola user ID, menginputkan user ke dalam aplikasi, mengubah level atau status user, membuat kategori kelas belajar.

b. Teacher/Lecturer : Menginputkan data login, mengelola materi ajar, melihat data kelas, membuat tugas, mengelola nilai. 
c. Student : Menginputkan data login, dapat kelas belajar, melaksanakan pembelajaran di dalam system.

d. Tamu : Melihat informasi, melihat kegiatan $e$ learning.

2. Analisis Alur Sistem Yang Berjalan Pada Mini Server LENTERA Menggunakan Diagram Konteks

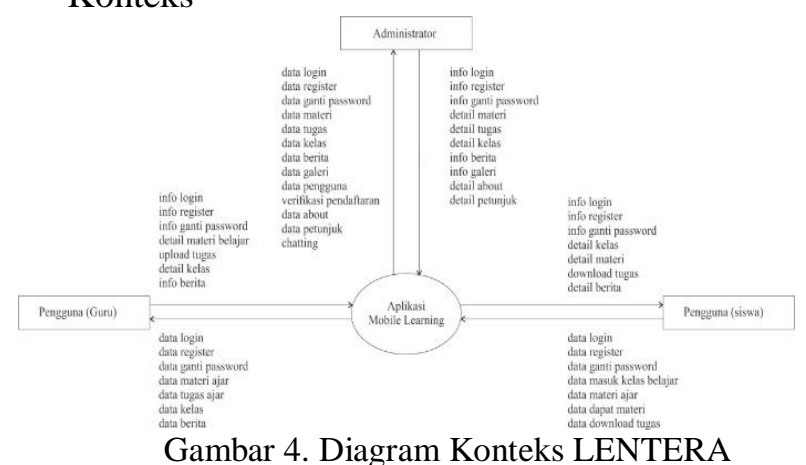

Context Diagram atau diagram konteks merupakan suatu diagram yang menggambarkan seluruh aktivitas baik masukan atau keluaran. Sistem atau aplikasi yang dimaksud adalah untuk menggambarkan sistem yang sedang berjalan (yang dibuat). Diagram ini merupakan gambaran umum sistem yang akan dibuat. Secara uraian dapat dikatakan bahwa diagram konteks berisikan siapa saja yang memberikan data masukan ke sistem/aplikasi serta kepada siapa data informasi yang dihasilkan sistem. Gambaran umum sistem yang mengalir di sistem ini yang memiliki 3 user utama yaitu admin, guru dan siswa. Masingmasing user memiliki flow/aliran data masuk dan keluar, untuk guru aliran data yg dimasukkan yakni register, login, membuat tugas, membuat kelas, kemudian siswa dapat menginputkan data register, mengumpulkan tugas, login dan masuk kelas bimbel. Sedangkan admin memiliki hak untuk mengolah seluruh data siswa dan guru.

3. Analisis Alur Program Menggunakan Diagram Sequence

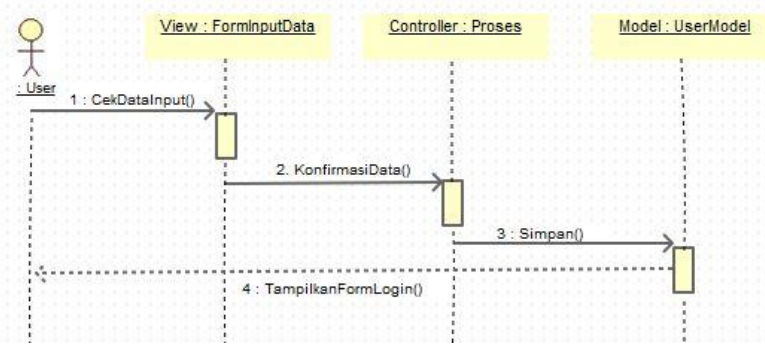

Gambar 5. Diagram Sequence System Mobile Learning LENTERA
Berdasarkan gambar diatas dapat dijelaskan bahwa proses berawal dari actor yang melakukan login, maka sistem akan melakukan validasi data login yang diinputkan berupa username dan password. Jika data valid, maka sistem akan membuat session sesuai dengan level actor yang login sehingga actor bisa melakukan aktifitas lain pada sistem.

4. Analisis Normalisasi Basis Data Sistem Media Literasi Digital Learning LENTERA

Proses normalisasi adalah proses penguraian data berdasarkan konsep RDBMS (relationship database management system)

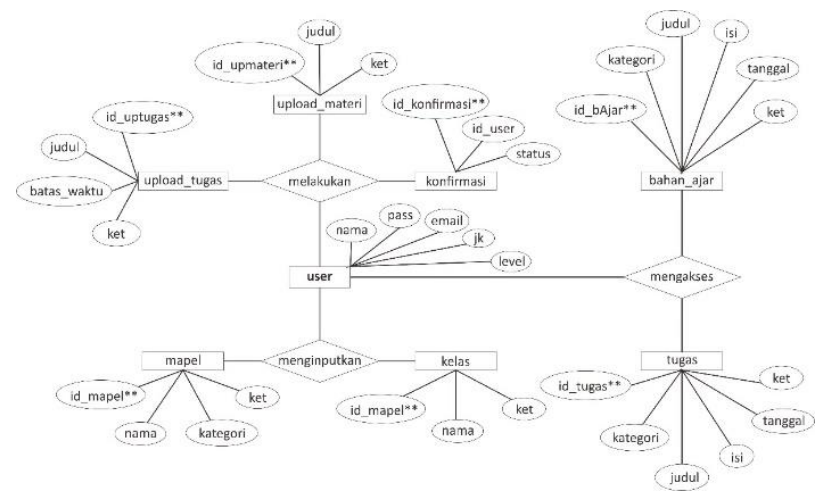

Gambar 6. ERD System Mobile Learning LENTERA

Relasi antar entitas sistem mobile learning LENTERA di atas menggambarkan tabel database yang saling berhubungan. Terdapat 5 entitas utama yang ada pada mobile learning system LENTERA yaitu user(guru, siswa dan admin), mapel, kelas, bahan ajar, tugas. Contoh entitas user dengan attribut nama, pass, jk, dan level akses memiliki relasi dengan entitas kelas dan mapel dengan relasi menginputkan. Sedangkan entitas user dengan level siswa memiliki relasi dengan entitas bahan ajar dan tugas dengan attributnya masing.

\section{HASIL DAN PEMBAHASAN}

Hasil dari perancangan sistem sumber media belajar dan topologi jaringan local yang di khususkan untuk satu kelas belajar efektif diintegrasikan ke dalam alat mini server dinamakan LENTERA. Alat dan sistem yang dirancang ini memungkinkan siswa untuk belajar dengan mengakses materi pembelajaran dalam bentuk video, audio, dan berbagai konten yang dikompilasi di situs offline, dengan menggunakan ponsel cerdas atau Komputer Pribadi (PC) mereka tanpa menggunakan koneksi internet . LENTERA dapat diisi dengan konten pembelajaran yang dibutuhkan oleh sekolah, guru, atau lembaga sebagai pengguna. Hal ini tentunya akan 
memberikan keuntungan tersendiri dari sekolah / institusi pendidikan yang relevan, karena secara tidak langsung dapat melindungi siswa dari mengakses situs berbahaya atau konten pornografi.

\section{KESIMPULAN}

Daya ungkit kegiatan/riset ini adalah memberikan kesempatan kepada siswa SMA dan SMK untuk memfamiliarkan penggunaan teknologi komputer dan jaringan internet tanpa terhubung ke internet [6]. Jadi, kondisi daerah 3T yang memiliki keterbatasan akses teknologi dapat diatasi dengan mini server ini. Sedangkan untuk pusat kota, kekhawatiran siswa mengakses konten negatif dan tidak relevan dengan pembelajaran dapat terfilter dengan adanya mini server ini [7].

Inovasi ini mendukungan penguatan sistem inovasi nasional yaitu pada aspek program pengembangan infrastruktur ICT (Information and Communication Technology) di lingkungan SMA dan SMK. Pemerintah akan membangun infrastruktur jaringan online skala nasional untuk kebutuhan interkoneksi antar sekolah (Zona Sekolah) di setiap wilayah Kota/Kabupaten seIndonesia. Dalam perkembangannya, infrastruktur jaringan online tersebut juga dihubungkan ke seluruh kantor Dinas Pendidikan Provinsi dan Kota/Kabupaten se-Indonesia sebagai simpul lokal JARDIKNAS di daerah (Zona Kantor Dinas). Dimana setiap kantor dinas pendidikan (sebagai simpul lokal) tersebut berkewajiban untuk mendistribusikan koneksi JARDIKNAS ke sekolah-sekolah termasuk Sekolah Menengah Kejuruan yang berfungsi sebagai ICT Center di daerah masing-masing [8].

\section{DAFTAR PUSTAKA}

[1] Fajri, Bayu Ramadhani. "Interactive Media Introduction To Motion Dance And Visual Meaning Of Topeng Malangan", 2019.

[2] Ganefri, Ganefri, et al. "Perangkat Pembelajaran Pedagogi Entrepreneurship Dengan Pendekatan Pembelajaran Berbasis Produk di Pendidikan Vokasi." Prosiding Seminar Nasional \& Internasional, Vol. 1, No. 1, 2018.

[3] Ranuharja, Fadhli, Oktoria Oktoria, and Nurindah Dwiyani. "Perancangan Sistem Informasi Jasa Penjualan Barang Berbasis Web Untuk Civitas Akademika Perguruan Tinggi di Kota Padang." Jurnal Vocational Teknik Elektronika dan Informatika 2, no. 2, 2018.
[4] Scott, Chyntia L. "The Futures of Learning 1: Why must learning content and methods change in the 21st century." Education, research and foresight working papers, available online at http://unesdoc. unesco. org/images/0023/002348 E 234807, 2015.

[5] Smaldino, Sharon E., et al. "Instructional technology and media for learning", 2008.

[6] Smaldino, Sharon E., Deborah L. Lowther, and James D. Russell. Instructional technology \& media for learning: Teknologi pembelajaran dan media untuk belajar. Prenada Media, 2014.

[7] Trilling, Bernie, and Charles Fadel. 21st Century Skills.: Learning for Life in Our Times. John Wiley \& Sons, 2009.

[8] Zubaidah, Siti. "Keterampilan abad ke-21: Keterampilan yang diajarkan melalui pembelajaran." Seminar Nasiendidikan dengan tema "Isu-isu Strategis Pembelajaran MIPA Abad. Vol. 21. No. 10. 2016. 